\title{
Medievalista
}

Online

$31 \mid 2022$

Número 31

A diplomacia dos reis de Portugal no final da Idade Média (1433-1495). Tese de doutoramento em História apresentada à Universidade do Porto, em Junho de 2021. Orientação do Professor Doutor Luís Miguel Duarte (Universidade do Porto) e coorientação do Professor Doutor Armando Luís de Carvalho Homem e do Professor Doutor Stéphane Péquignot

\section{Diogo Faria}

\section{OpenEdition}

\section{Edição electrónica}

URL: https://journals.openedition.org/medievalista/5200

ISSN: 1646-740X

\section{Editora}

Instituto de Estudos Medievais - FCSH-UNL

\section{Refêrencia eletrónica}

Diogo Faria, «A diplomacia dos reis de Portugal no final da Idade Média (1433-1495). Tese de

doutoramento em História apresentada à Universidade do Porto, em Junho de 2021. Orientação do Professor Doutor Luís Miguel Duarte (Universidade do Porto) e coorientação do Professor Doutor Armando Luís de Carvalho Homem e do Professor Doutor Stéphane Péquignot», Medievalista [Online], 31 | 2022, posto online no dia 01 janeiro 2022, consultado o 02 fevereiro 2022. URL: http:// journals.openedition.org/medievalista/5200

Este documento foi criado de forma automática no dia 2 fevereiro 2022

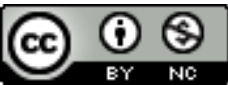

Mediavalista está licenciado com uma Licença Creative Commons - Atribuição-NãoComercial 4.0 Internacional. 
A diplomacia dos reis de Portugal no final da Idade Média (1433-1495). Tese de doutoramento em História apresentada à Universidade do Porto, em Junho de 2021. Orientação do Professor Doutor Luís Miguel Duarte (Universidade do Porto) e coorientação do Professor Doutor Armando Luís de Carvalho Homem e do Professor Doutor Stéphane Péquignot

Diogo Faria

\section{NOTA DO EDITOR}

Data recepção do artigo / Received for publication: 20 de Junho de 2021

A história desta tese tem alguma relevância para a compreensão da sua forma final e teve início no verão de 2013, com a apresentação de uma candidatura a bolsa de doutoramento. $\mathrm{O}$ projeto então submetido à Fundação para a Ciência e a Tecnologia intitulava-se "Relações diplomáticas entre Portugal e França (1325-1481)" e tinha pouco 
a ver com a dissertação de mestrado que se concluía pela mesma altura e era dedicada ao conhecimento da burocracia régia e da oficialidade da administração central no reinado de D. Manuel I'.

2 A reorientação da área de pesquisa tinha resultado de um conjunto de sondagens na historiografia internacional em busca de linhas de investigação no âmbito da história dos poderes do final da Idade Média que pudessem ser minimamente inovadoras, viáveis e enriquecedoras no quadro do medievismo português. Foi assim que se chegou ao conhecimento do essencial sobre a renovação da história da diplomacia da Idade Média, nos termos em que tem sido empreendida por autores como Anne-Brigitte Spitzbarth, Eva Pibiri, Isabella Lazzarini, Jean-Marie Moeglin, Karsten Plöger, Óscar Villarroel González e, sobretudo, Stéphane Péquignot ${ }^{2}$. Trata-se de uma história da diplomacia em que os primados do acontecimento isolado ou das visões geopolíticas e geoestratégicas, que tiveram grande fortuna nos séculos XIX e XX, foram substituídos por perspetivas mais holísticas, valorizadoras da infinidade de aspetos associados aos contactos entre governantes de entidades políticas distintas, tais como os documentos da diplomacia e os seus usos, as práticas de negociação, o perfil dos agentes envolvidos nestas relações e os rituais associados à sua concretização. Foi com um conhecimento pouco mais do que superficial sobre estas matérias, e tendo em conta um diagnóstico sobre o panorama da historiografia sobre as relações externas medievais portuguesas em que abundavam trabalhos sobre os contactos com os reinos ibéricos, com o papado e com a Inglaterra, com destaque para a tese defendida no ano anterior por Tiago Viúla de Faria sobre as relações de Portugal com Inglaterra durante a Guerra dos Cem Anos -, que se escolheu a França como estudo de caso. Em linhas gerais, o que se propunha fazer nesse verão de 2013 era investigar as relações luso-francesas dos séculos XIV e XV à luz dos temas, problemas e questionários que vários dos historiadores referidos aplicaram para os casos de outras potências da Cristandade medieval.

3 Apesar de a candidatura à bolsa de doutoramento ter sido bem-sucedida, a oportunidade que tinha surgido entretanto de participar num projeto do Instituto de Estudos Medievais da Universidade Nova de Lisboa dedicado ao estudo dos juízes de fora fez adiar por um ano o arranque do trabalho sistemático de investigação bibliográfica e documental. Ainda que o foco principal fosse outro, essa fase veio a revelar-se importante para o que viria a ser este projeto, uma vez que as explorações preliminares às fontes sobre a diplomacia medieval portuguesa rapidamente conduziram a duas conclusões: por um lado, afigurava-se genericamente viável estudar aspetos diferentes das relações externas da Idade Média - havia testemunhos sobre rituais, finanças, viagens, etc. -; por outro, o panorama documental do caso específico das relações com França parecia castrador desses intentos. Era possível, seguramente, saber mais e apresentar visões renovadas sobre os contactos entre os monarcas portugueses e franceses, mas não era esse o caminho para conhecer melhor como é que funcionava na prática a diplomacia dos reis de Portugal. Numa fase ainda precoce da investigação, o projeto foi reformulado e deu origem à tese defendida a 1 de junho de 2021, na Universidade do Porto, cujas coordenadas essenciais se procurou concentrar no seu título.

O recurso ao termo "diplomacia" foi feito com a consciência de que ele não existia na Idade Média, mas com a convicção de que é representativo de realidades que precedem o seu aparecimento em diversas línguas europeias no final do século XVIII. Na linha de autores como Françoise Autrand e Stéphane Péquignot, nesta tese entende-se por 
diplomacia o "conjunto de atividades de representação, de intercâmbio e de negociações políticas, realizadas em nome de um poder junto de outros poderes"3.

E trata-se, especificamente, da diplomacia "dos reis de Portugal", e não da diplomacia "portuguesa" ou do "reino de Portugal". Por um lado, porque a análise incidiu em concreto sobre os "negócios estrangeiros" dos monarcas de Avis com poderes equiparáveis de outras potências, e não sobre outras figuras ou instituições do reino que também os tinham, como membros da família real, bispos, ordens militares ou concelhos. Por outro, porque a dimensão pessoal destas relações é demasiado evidente.

Sobre a escolha da cronologia, há que enunciar e assumir a sua artificialidade e as razões práticas que a justificam. Os 62 anos que vão de 1433 a 1495 não correspondem a um período fechado, coerente e distintivo da história da diplomacia. Nem o início do reinado de D. Duarte nem o fim do de D. João II marcam qualquer rutura. Para encontrá-las, provavelmente, seria preciso alargar muitíssimo o arco cronológico. A opção passou por escolher uma época que estivesse documentada com testemunhos tipologicamente diversificados que permitissem abordagens com um mínimo de solidez aos aspetos da história das relações externas menos estudados em Portugal. Textos como o Livro dos conselhos de El-Rei Dom Duarte, o Livro de Apontamentos de Álvaro Lopes de Chaves, o diário da viagem do conde D. Afonso ao Concílio de Basileia, as crónicas de Rui de Pina, Garcia de Resende, Damião de Góis e vários autores castelhanos e aragoneses, tratados como os das Alcáçovas e de Tordesilhas, além de documentos avulsos como cartas de quitação de embaixadas ou cartas de instruções, viabilizavam a aplicação do tipo de abordagem pretendida ao século XV, em geral, e aos reinados de $\mathrm{D}$. Duarte, D. Afonso V e D. João II, em particular. $O$ trabalho seria enriquecido se também pudessem ter sido inquiridas com profundidade as governações de D. João I e D. Manuel I, mas afigurou-se impraticável adicionar 48 ou 26 anos à cronologia.

7 Foi já com este quadro cronológico e temático esboçado que se iniciou de forma sistemática a investigação empírica em fontes manuscritas e publicadas. Entre 2014 e 2017, foram consultados documentos em arquivos portugueses, espanhóis, franceses e ingleses. A generosidade de outros investigadores, os recursos disponíveis online e as fontes editadas proporcionaram acesso a testemunhos com outras proveniências e mitigaram as consequências da impossibilidade de explorar presencialmente acervos dos Países Baixos, da Alemanha ou do Vaticano. No início desta fase, com a colaboração de um informático, foi desenvolvida a base de dados que serviu para registar e organizar os elementos recolhidos, que se estruturaram em cinco fichas relacionadas sobre documentos, embaixadas enviadas, embaixadas recebidas, encontros entre monarcas e agentes da diplomacia. Textos, acontecimentos e homens. Foram estes os três eixos da informação à qual foi aplicado o questionário de que resultaram os seis capítulos da tese.

Os primeiros a serem redigidos foram o terceiro e o quarto, sobre as vistas régias e as embaixadas. A reconstituição tão exaustiva quanto possível da factualidade das relações externas deste período foi um dos principais objetivos da investigação, por cedo se ter percebido que isso era algo que estava por fazer e por se ter julgado fundamental para uma cabal compreensão do funcionamento de diversas dimensões da prática diplomática, tais como, por exemplo, a seleção dos embaixadores e a organização logística das missões. Com estruturas semelhantes, cada um desses capítulos abre com uma análise global dos acontecimentos, que tem como ponto de partida a história das palavras mais frequentemente utilizadas para designá-los. Segue-se um breve exame 
dos seus antecedentes na primeira dinastia e no reinado de D. João I e um olhar sobre a sua evolução entre 1433 e 1495. Por fim, apresenta-se um catálogo em que se detalha o enquadramento, os objetivos, os resultados, os aspetos logísticos e cerimoniais, as fontes e a bibliografia específica sobre cada um desses eventos.

9 A propósito das vistas régias, notou-se que, depois de terem sido muito frequentes até finais do século XIII, tornaram-se raras a partir de meados do reinado de D. Dinis e quase deixaram de se realizar durante as governações dos seus sucessores, ao ponto de entre as últimas de D. Afonso IV e as primeiras de D. Afonso V terem passado 102 anos em que, pelo meio, só houve umas. Podem ajudar a explicar este ocaso a estabilização da fronteira com Castela, o deteriorar das relações com o reino vizinho e o reforço dos meios para o estabelecimento de contactos com o exterior proporcionado pela curialização da nobreza e o desenvolvimento do desembargo. 0 cenário mudou a partir do reinado do "Africano", com 11 vistas em 35 anos, resultantes do estreitamento das ligações a Castela e da realização da muito excêntrica viagem do monarca a França. Já no reinado de D. João II, regressou-se à normalidade, praticamente sem vistas, exceção feita à receção em Setúbal de um príncipe da região da Senegâmbia, reflexo do estabelecimento de relações amigáveis com potências da África subsaariana. Por norma, a organização destes encontros obedecia a um conjunto de princípios que estavam bem sedimentados desde a época carolíngia, nomeadamente quanto à escolha do seu local. Simbolicamente, os espaços fronteiriços eram apropriados para aproximações de príncipes em igualdade de circunstâncias, por isso não admira que a área compreendida entre Elvas e Badajoz - aberta, plana e sem obstáculos - fosse uma das privilegiadas.

Muitíssimo mais frequentes eram as embaixadas, que neste período continuaram a ser sempre realizadas ad hoc. Foi possível identificar 113 missões promovidas pelos reis de Portugal durante estes 62 anos, correspondentes a um ritmo médio de 1,8 por anoritmo esse que foi intermitente e muito sensível às conjunturas, mas tendencialmente crescente entre os reinados de D. Duarte e D. João II. O quadro de destinos, que foram 20 , é substancialmente mais alargado do que os do tempo de D. João I e da primeira dinastia, fruto da inclusão entres os interlocutores dos reis de Portugal de várias entidades africanas e da multiplicação dos contactos com repúblicas e principados italianos. Ainda assim, o núcleo principal destes negócios não mudou assim tanto: na frente e com destaque continuaram Castela e o Papado. Muito diversificados, os motivos das embaixadas tinham quase sempre no horizonte as questões da guerra e da paz.

11 A abordagem a estes eventos constitui o eixo central da tese, mas não a esgota. Por isso, antes, em dois capítulos, procurou-se esboçar o quadro geral em que se desenvolveram estes acontecimentos e demonstrar a importância da escrita noutros contactos; e depois, noutros dois capítulos, tentou-se dar conta do perfil dos agentes envolvidos nas relações externas e traçar as linhas de força da organização, da logística e da concretização prática da diplomacia.

12 No primeiro capítulo, "O quadro elementar", arrancou-se com um ensaio historiográfico em que se destaca a excelência do trabalho do Visconde de Santarém e a relativa pobreza da história diplomática dos anos que se lhe seguiram, para depois se notar que a partir de meados do século XX houve um notável esforço de publicação de fontes, mas que, salvo algumas exceções e o que tem acontecido na última década, poucas vezes os investigadores portugueses incorporaram nos seus trabalhos as novidades desta área que iam ganhando vida no estrangeiro. Segue-se a apresentação 
crítica das fontes que sustentam a tese, que permitiu confirmar que os estudiosos da diplomacia medieval portuguesa estão longe de ter à disposição os "oceanos documentais" que se encontram, por exemplo, na Coroa de Aragão e na Borgonha, mas não estão assim tão carenciados de testemunhos de tipologias diversas que permitam a abordagem de assuntos que têm sido pouco explorados. Por fim, olhando à genealogia destes monarcas e aos formulários da correspondência diplomática de D. Duarte e D. Afonso V, foram elencadas as ligações dos reis de Portugal ao estrangeiro, dando-se conta de um alargamento significativo dos laços de parentesco com outros príncipes durante o século $\mathrm{XV}$, resultado de uma mais diversificada política de alianças da família real e, em grande medida, do casamento de D. João I com Filipa de Lencastre, que entroncou a dinastia de Avis na prolífica descendência de Eduardo III de Inglaterra.

13 O capítulo seguinte é dedicado à diplomática da diplomacia, o que significa que os documentos relativos aos contactos com o exterior são analisados sob um ponto de vista diferente: em causa deixa de estar a globalidade dos testemunhos de relações diplomáticas, mas exclusivamente os atos que resultavam diretamente dessas atividades. Num tempo que Isabela Lazzarini classificou como "era de comunicação multiplicada" ${ }^{4} \mathrm{e}$ em que a escrita estava na base do desenvolvimento dos aparelhos administrativos dos príncipes, eram vários os tipos de documentos que sustentavam as ligações ao estrangeiro, de que são exemplos os tratados, as cartas de crença, as procurações, os salvo-condutos e as cartas de instruções. Ainda que se preservem em quantidades residuais, em Portugal estes textos não tinham características substancialmente diferentes das dos que eram produzidos noutros espaços, podendo notar-se uma singularidade ibérica ao nível das línguas: numa mesma negociação, era possível que convivessem diversos idiomas, com cada uma das partes a expressar-se no seu. A evolução dos mecanismos de conservação dos documentos que tinham validade jurídica, com destaque para a prática, que remonta ao reinado de D. João I, de elaboração de cartulários temáticos dedicados às relações externas, testemunha a importância que era atribuída a estes atos no seio da administração do reino.

14 A preponderância da escrita na diplomacia também fica evidente no perfil dos agentes selecionados para representarem os monarcas no estrangeiro, objeto do capítulo cinco. Se é certo que os nobres nunca deixaram de ser maioritários entre o conjunto dos embaixadores, também é evidente que os letrados do desembargo - homens da confiança dos monarcas que tinham formação superior, dominavam línguas estrangeiras e estavam habituados a viajar - foram os que ganharam mais peso durante esta cronologia - correspondiam a um quinto dos embaixadores, mas estavam presentes em mais de metade das embaixadas. Neste tempo em que ainda não havia carreiras especificamente dedicadas aos contactos com o exterior e em que a maioria dos indivíduos que participavam nestas missões fazia-o apenas uma vez, começaram a surgir indícios evidentes de especialização de algumas figuras, com destaque para o caso excecional do Doutor João Fernandes da Silveira, nomeado para pelo menos 17 missões, nove delas em Castela.

15 A forma como as embaixadas e outros momentos relevantes da diplomacia se desenvolviam na prática é inquirida no último capítulo, dedicado às finanças, às viagens, aos mecanismos de recolha de informação, às cerimónias e rituais e ao acolhimento de embaixadores estrangeiros. $O$ leque de assuntos é diversificado, mas procurou-se o mesmo em relação a cada um deles: a partir de dados quase sempre fragmentários e de alguns estudos de caso, tentar oferecer visões de conjunto em que a 
realidade portuguesa fosse comparada com a de outros espaços. Em geral, concluiu-se que o reino português não escapou ao fenómeno de aprofundamento da "cerimonialização das relações diplomáticas" que José Manuel Nieto Soria identificou para o mesmo período em Castela $^{5}$. Ocasiões como a celebração de alianças matrimoniais e o envio e receção de embaixadas assumiram-se como momentos privilegiados de propaganda e legitimação da dinastia de Avis, que tinha como marca distintiva em diversas cerimónias o recurso a elementos simbólicos que remetiam para o exotismo das terras do Sul e do mar oceano.

Num segundo volume, apresentam-se em apêndice quatro árvores genealógicas, seis mapas, 93 notícias biográficas de embaixadores e as transcrições de 96 documentos, com destaque para: as escrituras da segunda parte do manuscrito 180 da Biblioteca Pública Municipal do Porto, constituída por um caderno coevo sobre a negociação e concretização do matrimónio da infanta Isabel de Portugal com o rei Juan II de Castela; as duas "cartas de Itália" relativas ao casamento de Leonor de Portugal com o imperador Frederico III, conhecidas através de cópias da British Library, que não foram publicadas por Rodrigues Lapa; os numerosos atos do códice 177 do fundo Manizola, da Biblioteca Pública de Évora, que dizem respeito aos contactos com o exterior de D. Afonso V e D. João II e envolvem maioritariamente a figura de João Fernandes da Silveira; e os exemplares da correspondência régia recebida pelo município eborense que tocam em assuntos como a receção a embaixadores e a organização do casamento do príncipe D. Afonso com Isabel de Castela.

Em jeito de síntese e de conclusão, assume-se como tese da tese:

18 A diplomacia dos reis de Portugal, entre 1433 e 1495, era uma área de incidência da governação com considerável dimensão pessoal, dirigida pelo rei e objeto de discussões e deliberações transversais a diversas estruturas da administração, não institucionalizada nem profissionalizada, mas tendencialmente mais especializada e formalizada, bem inserida numa cultura diplomática que era comum à generalidade do Ocidente medieval.

\section{NOTAS}

1. FARIA, Diogo - A chancelaria de D. Manuel I. Contribuição para o estudo da burocracia régia e dos seus oficiais. Porto: Universidade do Porto. Dissertação de mestrado.

2. Por todos, veja-se: MOEGLIN, Jean-Marie; PÉQUIGNOT, Stéphane - Diplomatie et «relations internationales» au Moyen Âge (IX $-X V^{e}$ siècle). Paris: PUF, 2017.

3. PÉQUIGNOT, Stéphane - "Les diplomaties occidentales, XIII ${ }^{\mathrm{e}}-\mathrm{XV}^{\mathrm{e}}$ siècle". In Les relations diplomatiques au Moyen Âge. Formes et enjeux. Paris: Publications de la Sorbonne, 2011, pp. 47-66.

4. LAZZARINI, Isabella - "La communication écrite et son rôle dans la société politique de l'Europe méridionale”. In GENET, Jean-Philippe (dir.) - Rome et l'État moderne européen. Roma: École française de Rome, 2007, pp. 265-285.

5. NIETO SORIA, José Manuel - Ceremonias de la realeza. Propaganda y legitimación en la Castilla Trastámara. Madrid: Nerea, 1993, pp. 133-135. 


\section{AUTOR}

\section{DIOGO FARIA}

Universidade do Porto, Faculdade de Letras, Via Panorâmica Edgar Cardoso, 4150-564 Porto,

Portugal. diogopintofaria@gmail.com. https://orcid.org/0000-0002-4640-6394 